\title{
The Co-construction of Agricultural Policies as a Bottom-up Adaptation Strategy to Climate Change and Variability (CCV) in the Regional County Municipality (RCM) of Haut-Richelieu, Québec
}

\author{
Cherine Akkari (Corresponding author) \\ Department of Geography and Environmental Management, University of Waterloo, \\ EV1-246, Ontario N2L 3G1, Canada.
}

Tel: 514-699-4328 E-mail: cakkari@uwaterloo.ca

Christopher Robin Bryant

School of Environmental Design and Rural Planning, Landscape Architecture Bldg., University of Guelph, Ontario N1G 2W1, Canada

\begin{abstract}
Claude Marois
Département de Géographie, Université de Montréal, Pavillon 520, ch. de la Côte-Sainte-Catherine, Local 331-3, CP 6128, succursale Centre-ville, Montréal, Québec H3C 3J7, Canada
\end{abstract}




\section{Abstract}

The overall objective of this article is to improve the understanding of the adaptation process to climate change and variability at the farm and the farming community levels through a mostly bottom-up process, while using the approach of co-construction in the Regional County Municipality (RCM) of Haut-Richelieu. To achieve this, the grounded theory approach is used.

The results show that all participants recognized the fact that climate change is happening. According to the farmers, climate change is the main determinant of adaptive capacity, followed by institutional support. Most farmers recognized that extremes (or variability) are associated with climate change. To a lesser extent, some farmers concluded that one should not separate climatic factors from non-climatic factors. The results also show that while some farmers recognized the positive and the negative side of climate change and variability $(\mathrm{CCV})$, the others are very optimistic about it as if they only see the positive side; there is nonetheless a need to see both sides of CCV. Moreover, there is still some uncertainty related to $\mathrm{CCV}$, which comes from disinformation and desensitization of the farmers mainly in relation to the causes of $\mathrm{CCV}$ along with the nature of climatic events. Despite the latter, the results show that agriculture in the RCM of Haut-Richelieu is well adapted to cope with climate change and variability. Farmers have already adopted measures to cope with CCV; however, they adapt spontaneously. Furthermore, nearly all farmers need help mainly from the agricultural public and private institutions to better adapt to CCV.

Keywords: agricultural adaptation strategies, agriculture, co-construction, collaborative research, Grounded theory, Haut-Richelieu.

\section{Introduction}

Globally, the intensity and frequency of extreme climatic events, such as heat waves, droughts, storms and floods, and sea level rise (Association of British Insurers, 2005) are increasingly recognized as related to climate change and variability (Huq et al. 2015; IPCC $2012 ;$ 2014). Since the 1960 s, worldwide losses due to natural disasters have roughly doubled (McEvoy et al. 2010). These climatic disasters can however create positive long-term opportunities such as creating institutional structures for disaster management and improvement in social networking, while at the same time having a detrimental cascading effect on biodiversity, ecosystems, water resources, and human livelihoods (Huq et al. 2015). All in all, CCV invariably affects human-environment interactions or socio-ecological systems (SES) and their processes (Jongman et al. 2014; Dunford et al. 2015), and of course all forms of human activity.

To deal with CCV, mitigation (that involves creating systems to eradicate the effects of CCV in terms of Greenhouse Gas emissions) is certainly important, but so is adaptation which involves enabling people and communities to adjust or adapt to the ongoing effects of CCV as well as to new or increased effects in the future (e.g. Pielke 1998; Bryant et al. 2000; Dilling et al. 2015). It is important to emphasize, however, that all territories (municipalities, cities, regions, countries...) have to cope with different circumstances, challenges and 
opportunities. For instance, it has been reported that the degree to which climate-related needs or constraints pertinent to water resources is regionally specific (Dilling et al. 2015). This has important implications for policies, plans and strategies for coping with CCV since it means that the 'one size fits all' approach is not likely overall to have constructive results (Bryant et al. 2016a). In the European Union, the importance of climate change still encounters difficulties in becoming integrated into planning policies, and there have been cases where populations have been so strongly opposed to integrating this problematic into planning frameworks that some local authorities have conceded in the face of such opposition (Bryant et al. 2016a).

Agriculture usually adapts well to average or normal climatic conditions, but on the other hand is very susceptible to irregular conditions or extremes (Reilly 1995; Smit et al. 1996; Risbey et al. 1999 cited in McEvoy et al. 2010). Moreover, there has been a recent paradigm shift in human environment studies from adaptation studies focussed on the potential impacts of CCV on crop yields to studies analyzing and highlighting the importance of human agents, along with other factors that influence the adaption decision-making environment in the process of adaptation (Akkari and Bryant 2016; Bryant et al. 2016a; b). To date however, research on the latter is still not flourishing especially in terms of the determinants of the farmer's decision-making environment generally, and in Québec more specifically (Dale et al 2010; Daouda et al 2015). The objective of the present study is to improve the understanding of the processes of adaptation and adaptive capacity at the farm and the farming community levels through a mostly bottom-up process, basically using the approach of co-construction, which can be used to construct policies, programs and projects at all scales such as projects for adaptation to CCV for farmers (Akkari and Bryant 2016). To achieve this, the main phases of the grounded theory approach are used, which are: data collection, note-taking, coding and formulating theories (or 'memoing'). At the same time, grounded theory helps in the implementation process of the co-construction approach. Furthermore, this study is unique because it contributes to the adaptation research on the determinants of the farmer's decision-making environment.

\section{Study Area and Methods}

\subsection{Study Area}

The total surface area of the RCM (Regional County Municipality) of Haut-Richelieu is about $996 \mathrm{~km} 2$ with a total population of about 117050 inhabitants in 2013. It contains 14 municipalities. Bordering the United Sates in the south, the RCM of Haut-Richelieu is located in the lowlands of the St-Lawrence and more precisely in Montérégie, where climate and fertile soils are favorable for farming. Precisely because of the importance of agriculture in this region, it was split into two parts, namely the East and West Montérégie (Figure 1). In the latter, of which the RCM of Haut-Richelieu is part, agriculture is an important economic activity. It is known as 'the garden and the orchard' of Québec and owes its agricultural vocation to a relatively mild climate and the good quality of its soils. Soil categories 1 and 2 (categories of the Canada Land Inventory) are the most preferable for agriculture and are predominant in Montérégie West, including the RCM of Haut-Richelieu. 


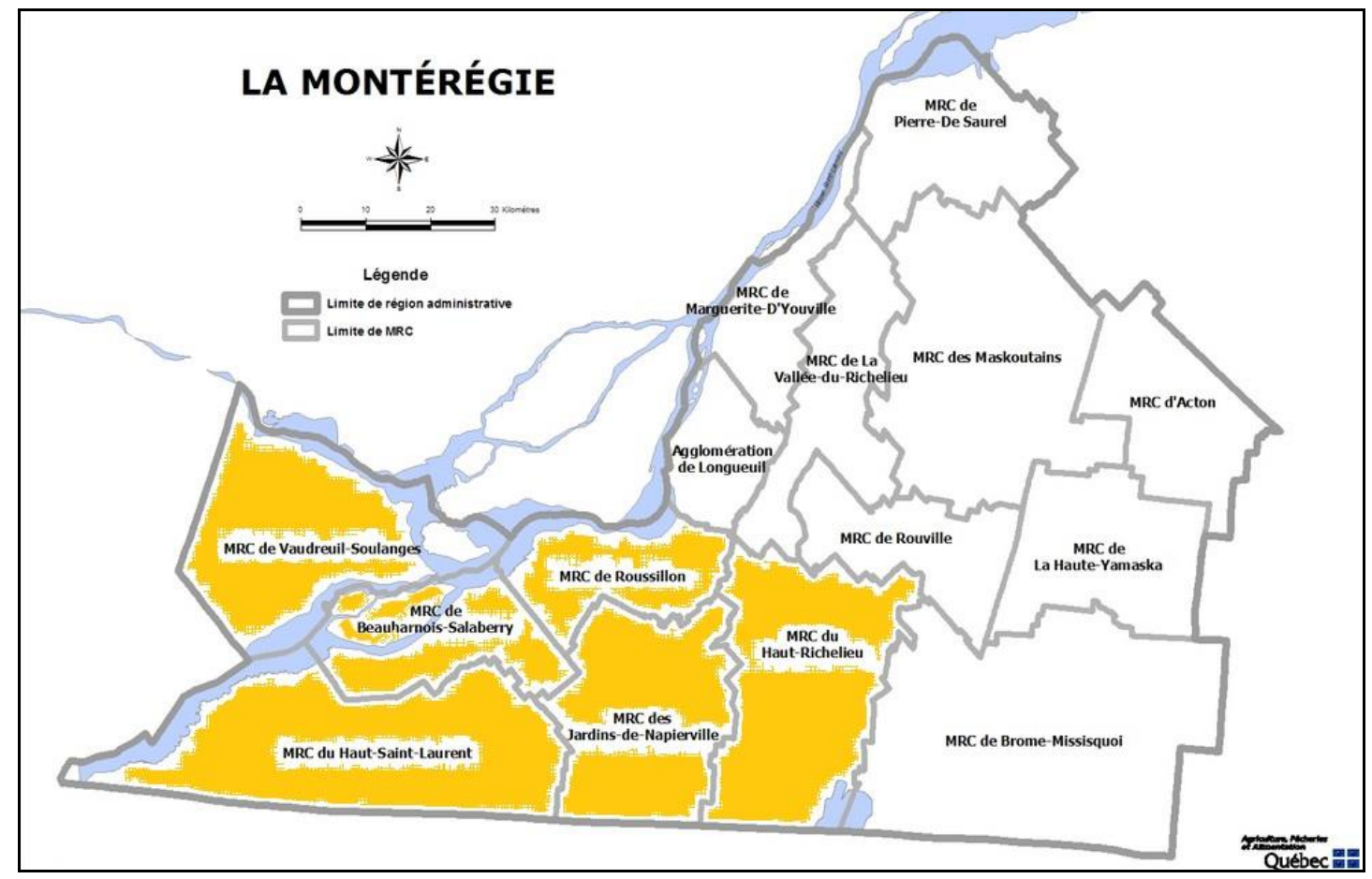

Figure 1. The RCM of Haut-Richelieu, Montérégie West (represented in Orange)

\subsection{Data Collection}

One of the main advantages of using the co-construction approach is to emphasize a better exchange of tacit knowledge, an essential component in any adaptation process. Tacit knowledge is best described by face-to-face interactions, social and cultural commonalities, and a shared understanding and language in a specific knowledge field. Practically all of which happen in our case study at the regional scale. Besides, local knowledge and experience that have occurred over time can help identify adaptation options and contribute to the formulation of policies or recommendations that are specific to the region under study.

Since the co-construction of local initiatives developed through a bottom-up approach eventually can lead contribute to agricultural public policies, the methodology employed here is based on grounded theory. The latter began as a bottom-up method, based upon actual research experience (Akkari and Bryant 2016). Grounded theory is used to aid in the implementation process of the co-construction approach (Figure 2), mainly in three ways: (1) it helps in identifying the actors in the preparation phase, (2) it helps prioritize and validate the principles or theories through coding the empirical data, that comes from the involvement of the farmers in the selection phase, and (3) it brings reflexive and prospective evaluation, through formulating policies or recommendations, in the validation phase. 


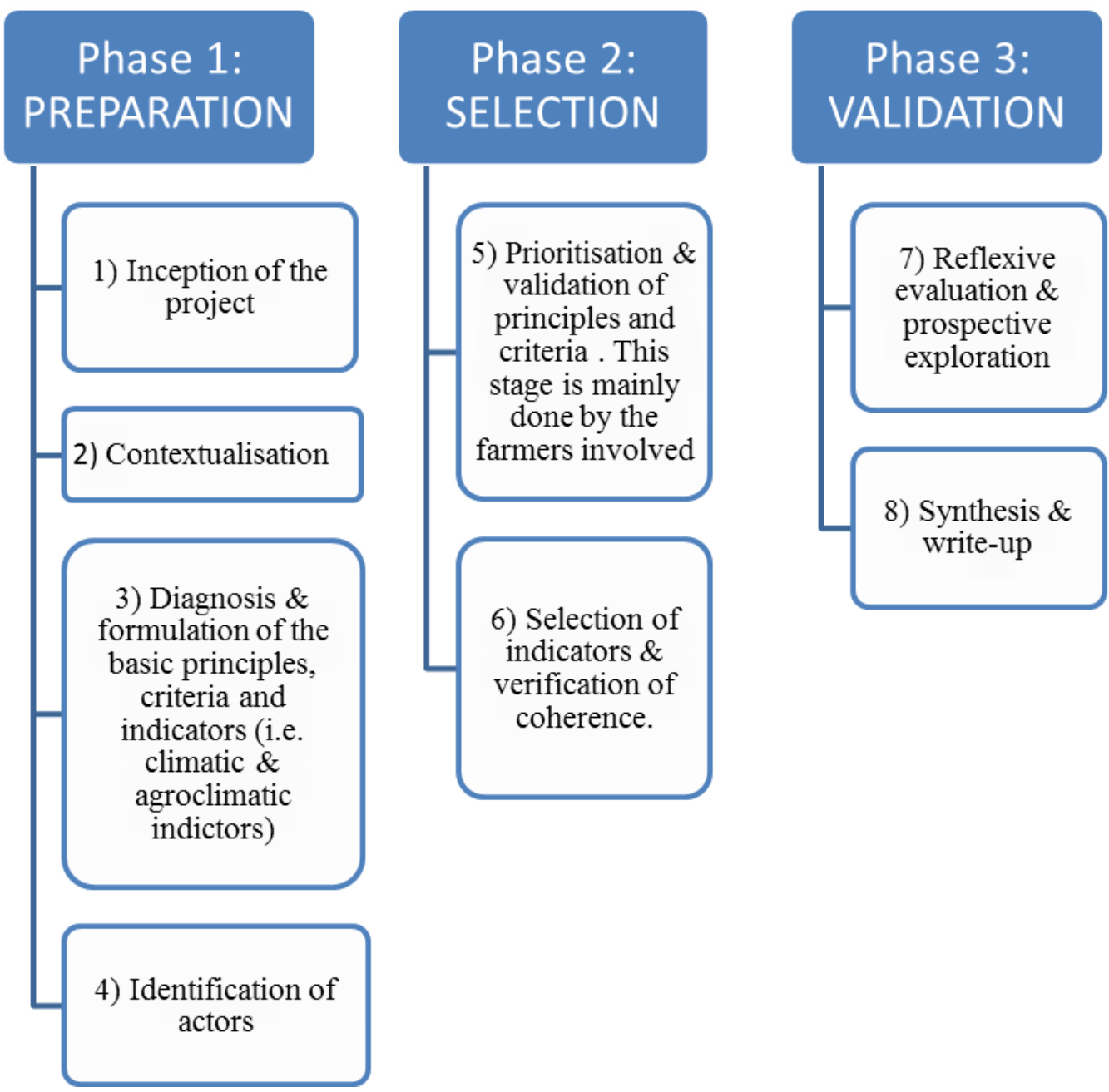

Figure 2. Implementation process of the co-construction approach.

From a bottom-up perspective, there are similarities between the co-construction approach and the grounded theory approach in terms of data collection and analysis (Akkari and Bryant 2016). According to Glaser and Strauss (1965), the theory emerges from a process of data collection through primary data (i.e. interviews and/or focus groups) and secondary data (collected from literature review and data from organisations such as Statistics Canada and other websites) (Figure 3). The theory is formed based on actors' issues and representations, thereby encouraging their appropriation. 


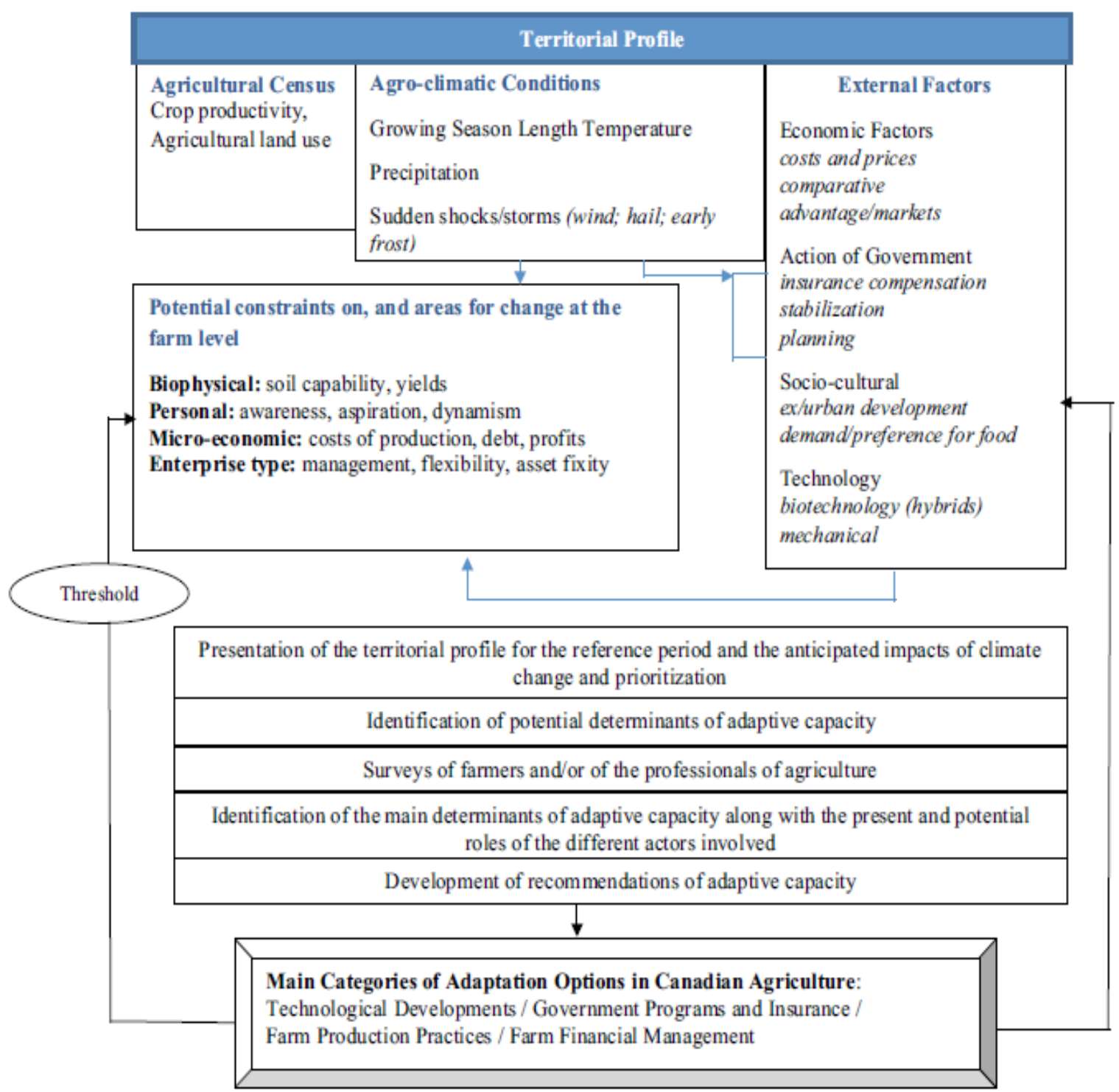

Figure 3. Steps of the methodology used in grounded theory as well as in the co-construction approach.

At first, the recruitment of the participants was attempted via more formal structures or organisms, such as the UPA and agro-environmental clubs (AEC), to reach the possible maximum number of actors. However, with the failure of the latter due to administrative and bureaucratic barriers, an informal approach was taken and it turned out to be much more successful particularly in terms of time required. As a consequence, the main primary data comes from interviewing one type of group of actors - farmers, since they are the ones who are actively involved in the process and consequently they are the ones who will have to diagnose, design, implement, monitor, evaluate, or significantly change their behaviour or are financially personally affected by any policy or program that governments may develop. Since the majority of the farmers mentioned the importance of agronomists, the other primary data comes from a focus group involving agronomists, and it was used for cross-checking the different information provided by the farmers. 
2.2.1 Size and type of sampling

Glaser (1998) states that within classic grounded theory there is no sample size, nor are there limits set on the number of participants or data sources; it just involves sampling for saturation and completeness and is basically theoretical, which leads to a sample for verification rather than a representative sample. According to Stern (2007), sampling size is not a very important criterion in a qualitative research approach as long as the researcher can identify the key participants for his/her research objective. In addition, it is the responsibility of the researcher to be able to establish confidence between him/herself and the respondents. For these reasons, the respondents were selected based on the snowball sampling strategy, which was originally developed by Coleman (1959) and Goodman (1961) as a means for studying the structure of social networks. Snowball sampling is one of the three most common sampling methods used in qualitative research (Mack et al. 2005). It is a strategy that helps to:

(1) Identify information-rich cases (or the well-suited interview participants),

(2) Recruit hard-to-reach (or hidden) populations, that is, groups that are not easily accessed through other sampling strategies; this underlies the non-probabilistic form of this sampling strategy, and

(3) Establish a trust between the interviewer and the interviewee (mainly because it takes advantage of the social networks of identified respondents).

\subsubsection{Semi-structured Interviews}

Since the main targeted audience are the farmers, taking into account their hectic schedules was a must for the planning of the interviews. Therefore, contacts with farmers started at the end of the Fall season. The first initial contact was made by phone. Its objective was to explain to the participants the research objectives for this thesis and ultimately to seek their agreement for participation in the interviews. An appointment was made only after receiving the formal approval of the farmer. The interviews were conducted either at the farmer's home or at his/her farm. At the end of each interview, the respondent was asked to provide the coordinates of other farmer(s) in the area who might be interested in participating in the study. This approach proved to be very effective in the sense that sending a letter of introduction to the participants was not needed. Indeed, using the snowball method was very effective because the existing social relations between farmers were skilfully utilized, as discussed in the previous sub-section 'Size and Type of Sampling'.

Primary data collection was undertaken by carrying out 15 interviews in total, for a period of around 4 months (from November 14/ 2014 until February 10/2015). Each interview did not take more than 1 hour. Even though contacts started to be made at the end of the Fall of 2014, farmers were still quite busy during this period in the growing season; so interviews were organized to not be too time-consuming for the farmers. Each interview was individual and registered on an audio-tape with the agreement of the farmer. Fortunately, all 15 farmers contacted agreed to have their answers or discussions registered. And of course, notes were also taken during each interview. Later on, the interview recordings were transcribed 
verbatim. Further and since the majority of the farmers mentioned the importance of the agronomists, a focus group between three agronomists was undertaken on March 25, 2015, in the municipality of Napierville to glean new information and/or to cross-check the various information provided by all 15 farmers. The focus group lasted 1 hour precisely and all three agronomists in the focus group agreed on registering the discussion as well.

The interviews began with general questions that help determine the profile of the participant (i.e. municipality, sex, age, type of production and total cultivated surface area). The other questions are open-ended and they explore the set of issues about adaptation to climate change and variability in the RCM of Haut-Richelieu. More precisely, the questions explore how farmers view climate change, how they view adaptation in the context of climate change and what they have done (i.e. which strategies if any have they taken?) to adapt, and what they consider they need in order to better adapt. Some questions encourage the farmer to analyze his/her position in relation to the global warming phenomenon (e.g. "Do you think your farm is already adapted to climate change?" How? or "Do you think that agriculture in the region can adapt to climate change?"). Other questions led the farmer to take a position in relation to climate change (e.g. "Do you think that agriculture should adapt to climate change?", or "What are the determinants of adaptive capacity by order of importance?", or "What are the factors that guide you in the selection of crops for your farm?").

\section{Data Analysis}

A Grounded Theory study begins with a general opening of the subject area (Dey, 1999). From this initial point, the study is continually focussed towards an area of social concern. Once a data site has been selected, collection of data (primary data) begins, which is usually in the form of open-ended interviewing and transcription (and transcription is needed to complete the note-taking process), but can include acquisition of secondary data such as documents and literature. By saying "all is data", Glaser meant that "exactly what is going on in the research scene is the data, whatever the source, whether interview, observations, documents. It is not just what is being, how it is being and the conditions of it being told, but all the data surrounding what is being told" (Glaser 2001).

\subsection{Coding}

The process of coding begins right after the collection of empirical data. Coding implies categorizing the data to reflect the various issues represented during the interviews.

Coding is the preliminary step in processing the results of the interviews. It allows the conversion of the data from the questionnaire survey to a coding scheme where each response category is associated with a specific binary code. After associating each response category with a specific binary code, Excel and SPSS were used mainly to produce a table of frequencies along with the variables. Results are considered significant (in terms of a majority basis) when the frequency is at least $73 \%$.

\section{Results of the Open-ended Questions}

This sub-section presents the analysis of the five principal categories of open-ended questions, 
i.e.:

1) Advantages and challenges of agriculture in the RCM of Haut-Richelieu,

2) Strategies and measures taken by the farmers to adapt to $\mathrm{CCV}$,

3) Actors involved along with their current and potential roles in helping farmers to adapt to $\mathrm{CCV}$, and

4) Determinants of adaptive capacity.

\subsection{Advantages and Challenges of Agriculture in the RCM of Haut-Richelieu}

In this section, farmers spoke about the advantages and difficulties they face during their tasks. While farmers in the RCM of Haut-Richelieu recognize that having a significant volume of major crop production - with or without animal farming - is an advantage for their region, they also acknowledge the negative consequences that farm consolidation is having on local, regional and national levels.

"Having several farms with a strong vocation on major crop production is very beneficial for the image of our RCM" [Farmer B]

However, as negative consequences:

"Intensive agriculture and monoculture are destroying our farms, rendering our soil more vulnerable than ever. We used to have more trees and animals than now" [Farmer O].

"For a small rural municipality, we are treated like any other urban or peri-urban municipality in the RCM. It is not fair given the fact that the conditions between municipalities are different" [Farmer J].

"There are lots of governmental subventions for the producers of corn and soy, but not for other crops like hay ("we are punished because we grow hay; because we do something good for our environment!') or any other type of production (i.e. organic farming)" [Farmer M].

"In Québec, we have lots of policies and regulations, which constitutes a barrier to our food production. So, it is clear that policies are more important than climate change. We have to constantly feed our region and the world, to financially thrive, while we are competing with other countries where production costs are lower and regulations are less present" [Farmer $\mathrm{B}]$.

Even the municipal taxes are considered as barriers for the farmers' adaptation to CCV.

"In addition to dealing with heavy rain events, you have to pay municipal taxes for forests ("some farmers cut the trees to produce more corn and soy") but it does not work like this; it's not to our advantage. Municipal taxes must be removed and the government has to pay it like in Europe because simply it is not to our advantage" [Farmer M].

Another challenge on the regional and local scales is the preservation of agricultural land in the face of unprecedented urban sprawl and industrialization. For most of the farmers, the proximity to urban areas and high land speculation (i.e. high price of agricultural lands 
associated with high competition for agricultural land purchases) are seen as a significant pressure on rural areas.

"There are lots of demands on building commercial parks in the municipality of Saint-Jean-sur-Richelieu" [Farmer N].

"The government is taking the good agricultural lands for the development of the highway 10-30. Therefore, the solutions that the government has are not realistic because they are short-term solutions" [Farmer M].

There is a minority of the interviewees which views the presence of investment funds as a good opportunity.

"Agriculture in our region is quite well adapted because of the presence of investment funds" [Farmer E].

These investment funds are also a competitor for the upcoming generation of farmers, which makes it more difficult for land acquisition by them. It is understandable that the shareholders of the funds want to stabilize their returns and diversify their portfolios by buying farmland. But if they buy land at much higher prices than what farmers would pay for them, the farmers may not be able to touch the expected returns and even crash if the evolution of commodity prices is not favourable. The latter encourages the consolidation of farms, which is very risky. The needs for farm succession and for agricultural labour were also highlighted by some of the farmers.

"Since there are some young people who are interested in farming, they go and study agriculture in MacDonald College or in Saint-Hyacinthe. However, the majority of them does not have money or a sufficient amount to operate a farm. It is unfortunate" [Farmer B].

The fortunate ones are those who make their farm a family (or inherited) heritage.

"I do not have a succession problem on my farm. I have a son who wants to continue to help me on the farm. He is in his last year at McDonald Campus. Moreover, my father who is 81 years old is already helping me" [Farmer $\mathrm{K}]$.

"We need labour to help us in farming and in accounting. A farmer works 24/24 hours" [Farmer I].

On the other hand, the proximity to urban areas has its own advantages such as the ease to hire labour (but at the same time, there is also frequently more competition for the labour), the access to inland infrastructures (which facilitates the exportation process), and the proximity to private companies (e.g. ethanol companies) that consume the grains (which in return also makes transportation of grains cheaper).

As mentioned earlier, agriculture is one of the most vulnerable sectors to climate change and variability. Agricultural producers in Montérégie suffer the negative effects of global warming as well as those of other agricultural regions of Québec. In fact, all producers admit having seen a changing climate, which is not what it was before. The seasons are increasingly unstable especially when excess rainfall is often followed by periods of drought. This often 


\section{Macrothink}

Journal of Agricultural Studies

ISSN 2166-0379

2017, Vol. 5, No. 2

results in delays in seedling dates, which have an impact on yields. Figure 4 ssummarizes the most recurrent climate events by order of importance over the last twenty years according to respondents.

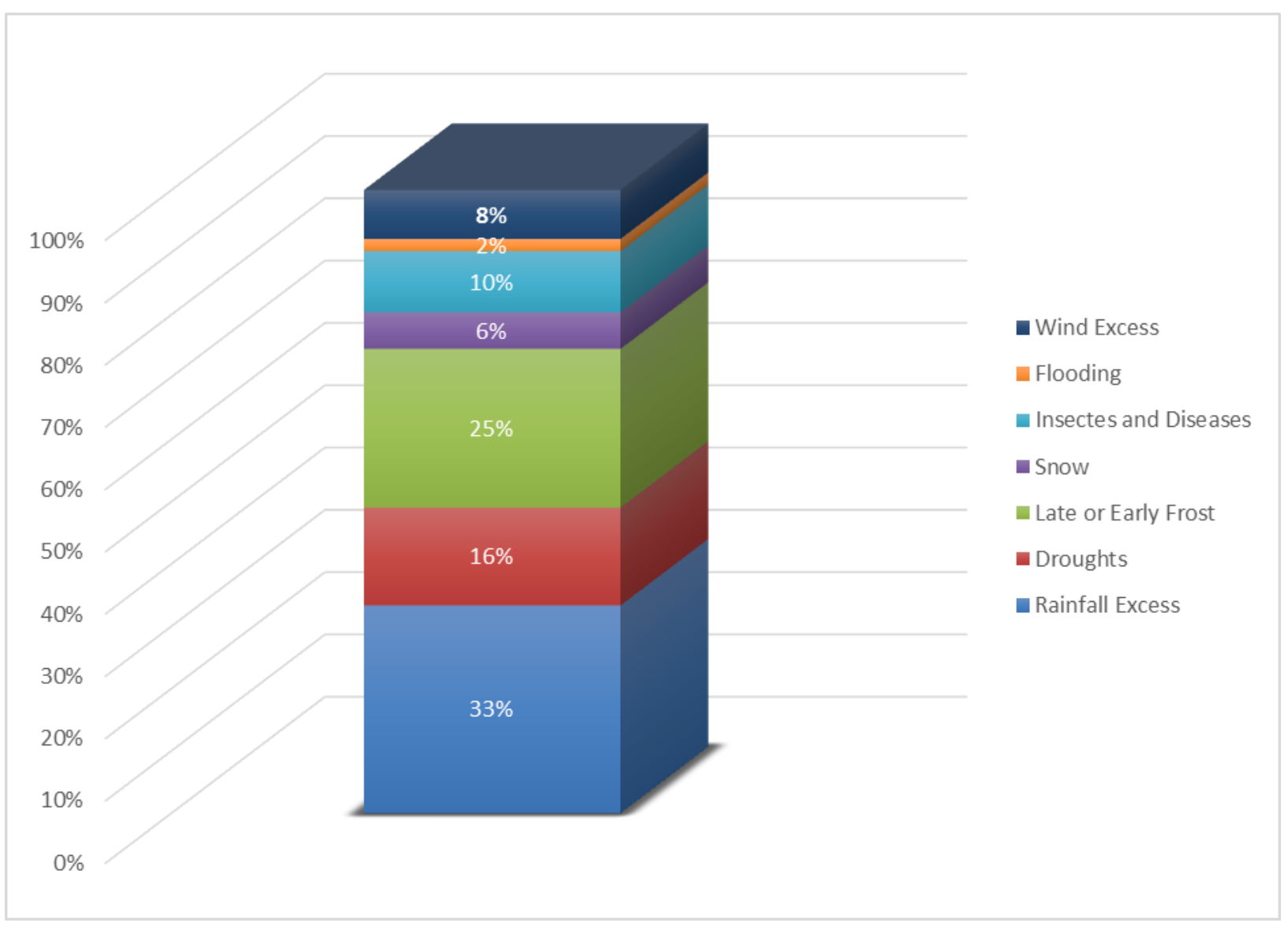

Figure 4. The most recurrent climatic events by order of importance over the last twenty years according to respondents, RCM of Haut-Richelieu, Inquiry 2014-2015.

"We have already started to adapt. It has been several years since we had to begin to adapt; that's for sure... especially rain - rainfall excess is incredibly abundant in our region. It is much easier to deal with insects since they are not very recurrent and much easier to treat" [Farmer B].

"Adaptation is to have vegetables that are of good quality despite climatic extremes (i.e. droughts or rainfall excess" [Farmer F].

"In my opinion, the question of adaptation is a personal matter. For me it is an emergency to adapt. There is little snow in the RCM of Haut-Richelieu. Summer temperatures are very hot and we are having floods that we never had before" [Farmer N].

Beyond the sensitivity of agriculture to climate change and variability, some farmers 
acknowledge the beneficial aspect of climate change such as the increase in the length of the growing season. However, and while acknowledging the latter, farmers are still not sure of the length of the growing season. While some see it as long or getting longer, it is still short to others.

"We adapt when it is necessary. Everything depends on the observation. The average of crop maturity is earlier than that of the last ten (10) years. Thirty (30) years before, we harvested the Macintosh on 21 September. Now we harvest the Macintosh on the 9th or 10th of September. Rainfall became more abundant in the last ten years or so; variation in precipitations is very huge" [Farmer B].

"If the growing season continues to increase, we might plant peanuts" [Farmer E].

"Climate change is very beneficial because it implies a warmer climate, which is very beneficial for my production. An addition of $10^{\circ} \mathrm{C}$ will not have any negative effect on my yields" [Farmer A].

"Climate change is in our favour. We like it. The winter is less long. And there is more CO2 in the atmosphere, which means crops grow better. Fertilization is still low though. However, the diesel that is being burned has to be cleaner now, which means low sulphur (good for those who have asthma) ... So now we have to put extra sulphur in our fields" [Farmer N].

While few do not feel the effect of climate change, they do recognize that climate change is mostly man-made.

"We do not feel completely the effects of climate change here. We are not in a flood zone... besides, climate change is more related to how we cultivate. Deforestation has an impact on global warming of the planet. Agriculture has changed-more machinery and fewer animals. The soils are depleted. More corn and soybeans, fewer prairies. And less and less farm succession" [Farmer H].

\subsubsection{Uncertain Future}

Despite what is being said about the effects that climate change has on agriculture, it is obvious that farmers live in uncertainty. For some, inaccuracy is present in weather forecasts (e.g. unpredictability of specific growing season conditions) or to the vague consequences of climate change presented by the media.

"Weather forecasts are not accurate at all (Saint-Bernard and Lacolle weather stations); so we look at the moon (an old farm saying)" [Farmer M].

Another uncertainty is related to the $25 \%$ cut in agricultural support programs (or agricultural insurance subsidies), particularly the elimination of the income stabilization insurance program.

"When the 2011 Lake Champlain and Richelieu River floods happened, my crops were largely affected (because my farm neighbours the Richelieu River). Though I was insured, the agricultural support programs didn't really help me; I had to compensate for the majority of the losses by myself" [Farmer N]. 


\section{Macrothink}

Journal of Agricultural Studies

ISSN 2166-0379

2017, Vol. 5, No. 2

To summarize what has been said above, CCV is already affecting agriculture in the RCM of Haut-Richelieu. Farmers in the RCM of Haut-Richelieu acknowledge climate change and suffer its consequences, although it is not as bad as in other regions. Besides CCV, agriculture is confronted by many challenges such as globalisation, proximity to urban areas, access to investment funds, the problem of farm succession and some drastic agricultural policies. It is also clear that outside the media world, farmers do not have a complete understanding of climate change, which aggravates in return the uncertainty related to climate change. In addition, claims about weather forecasts have already stirred up some controversies. According to M. Phillips of Environment Canada, "Environment Canada's forecasts aren't always right, but that their predictions are more realistic than the almanac" (Coorsh 2014). It is important to note here that farmers (or the general public) need to really understand that some aspects of the weather (such as temperature and pressure, or even mean wind speed at some broad spatial scale) are rather easier to predict than others (e.g., precipitation, cloudiness, or local turbulence). Hence, if someone is particularly sensitive to rain and snow, that person may hold the belief that the weather man does not know what he's talking about, while another person who is more attuned to temperature forecasts may claim that the same weather man is actually doing quite well. Therefore, the reasonableness of popular statements may also be variable depending on what they claim to predict and who they are. Furthermore, any reduction (or removal) of crop insurance subsidies would mean that risks would be more fully borne by farmers, in which case a more careful consideration by farmers of the likelihood of certain CHU (Corn Heat Units) accumulations might be warranted - rather than weighting expectations heavily on the conditions of the previous year.

4.1.2 Strategies and Measures Undertaken by Farmers of the RCM of Haut-Richelieu to Adapt to Climate Change and Variability

This sub-section or second category is about how the respondents see adaptation and how they adapt.

The second question of the questionnaire is about the definition of the word 'adaptation' in the context of climate change and variability. $60 \%$ of the participants recognized adaptation as a way to improve their situation on the farm to cope with the extremes (or variability) that are associated with climate change. To a lesser degree, some farmers concluded that one should not separate climatic factors from non-climatic factors in the process of agricultural adaptation to climate change and variability. The other minority (representing 13\%) sees that reducing the GHG effect is a means to cope with CCV. It seems that for this group of participants (the 13\%), adaptation naturally implies mitigation (and vice versa).

For the participants, the word 'improve our situation' means to increase the yields, to have products of good quality and to not completely suffer the negative consequences of climate change. All in all, participants have acknowledged the fact that climate change is happening. There is one farmer who said that farmers are not in the adaptation phase yet because they are currently suffering the consequences of $\mathrm{CCV}$.

"We are observing the changes and we are not at the stage of adaptation.

I use the word 'suffer', we are suffering" [Farmer D]. 
In addition, and while seeing that the adaptive capacity of the region is well developed (the range is between fair and excellent), the majority of the participants also agreed that adaptation of agriculture to $\mathrm{CCV}$ is a must and a non-reversible process (in the sense that climate does not adapt to agriculture). Some of the respondents added that adaptation is an on-going process, a mode of survival acquired by constant learning and experiences.

"Adaptation is a must; we do not have any other choice. Adaptation is an on-going process; it is not like a light that you turn off and on whenever you want. Climate does not adapt to agriculture" [Farmer G].

In terms of intent and purposefulness, adaptation in the RCM of Haut-Richelieu is basically spontaneous because it is taken by private actors - farmers and/or agro-environmental clubs of farmers. The majority of the respondents talk to or frequently have an agronomist on their farms (or is a member of an agro-environmental club). And there is one farmer who already has an experience of more than 11 years in doing research on his farm (farmer and agronomist at the same time, in other words). However, some of the money that goes to the agro-environmental clubs comes from the government; so we can say here that the government is indirectly or partially involved in the adaptation process of the farmers. Also, farmers know the crop varieties that are better adapted to climate through their own trial and error.

"We know the best adapted vegetable varieties by trial and error" [Farmer F].

"We do experiments on the field crops, especially for the cows. Every year, at the end of the growing season, we compare different varieties of corn and soybeans on a test plot to see which variety is the most adaptable" [Farmer M].

However, farmers do the latter to gradually phase out one crop variety in favour of another that seems to cope better under current climatic conditions. Thus in this case, under the private sector mainly, and with a partial intervention of the public sector, adaptation alternates between autonomous and planned adaptation.

In terms of timing and duration, the majority of the participants adapt in a proactive way (strategic or long-term responses) while the minority adapts in a reactive way (tactical or short-term response.

Eventually and after a while, when adaptations are consciously planned there is an interest in assessing performances of such strategies. Fortunately, the majority of the respondents systematically evaluates the types of adaptation. They do so by evaluating the yields and/or detecting the presence of insects and diseases, and some of the public actors (e.g. public agricultural institutions such as MAPAQ (Ministère de l'Agriculture, des Pêcheries et de l'Alimentation du Québec) and FAQ (Financière agricole du Québec)) are involved in such evaluations. Others do not evaluate their types of adaptation because they simply trust the private companies to offer them the different and appropriate varieties of cultivars. This confirms what has been said before, which is that even in autonomous adaptations, private actors plan for adaptation without the deliberate intervention from the government, but they do not act in isolation from the existing cultural, political, social and market institutions. 
Regarding the cultural practices that aim to protect soil against erosion, they are still present according to the respondents. Moreover, when it comes to the types of adaptation in the RCM of Haut-Richelieu, they belong to two categories identified by Smit and Skinner (2002), which are: farm production practices and farm financial management. Question 8 is about the measures and strategies that farmers take to better cope with CCV. One of the steps that the participants take before undertaking an adaptation activity is investment (i.e. subscribing to crop insurance, investment in drainage; $70,000 \$$ for 40 hectares), which belongs to the category of farm financial management.

\subsubsection{Actors Involved Along with their Future Potential}

It is obvious that the agro-environmental clubs (AEC) (whose Agronomists usually provide yield maps, cumulated on a GPS, to see which areas have lower vs. higher yields) are the actors who accompany the participants (not all farmers are members of such clubs, but many are) for most of the time, especially when in need for consultation or support. That is when farmers systematically evaluate their adaptations. Agro-environmental clubs offer professional support to all farmers who pay a membership fee and /or an hourly rate. At the same time, AEC are funded through the Prime-Vert program and the Partnership Agreement MAPAQ (Ministère de l'Agriculture, des Pêcheries et de l'Alimentation du Québec) and the UPA relating to AEC consulting services for sustainable development of the farms. Agricultural public institutions like UPA, MAPAQ and FAQ (Financière agricole du Québec, which manages the crop insurance programs) also help the farmers to some extent (e.g. diffusion of information, analysis of data about estimated yields and volumes of crops). However, they help farmers in their adaptations mostly in an indirect way. For instance, the participants look at the local weather forecast all the time and it is usually the government or its associated public institutions that develop early warning systems to provide daily weather and seasonal forecasts. Private companies have a special place too, by offering personal and practical support and guidance to the farmers. However, few farmers mentioned them during the interviews. While some trust them and see them as an opportunity in technical and practical terms, others do not because they see them as sellers of inputs for the farmers. This was also emphasized in Daouda et al. (2015).

"It has been 2 years that I trusted the private companies in offering me the different varieties of cultivars, which is ideologically unfortunate” [Farmer C].

"One should not trust the private companies all the time" [Farmer L].

Moreover, the majority of the participants said that they need help - financial, personal or both - to enable them to adopt better adaptation strategies in the face of $\mathrm{CCV}$, and that that help should come from a different variety of sources.

"There is always a place for improvement. I do not trust the government - labour intensive and more risk. It's too slow... even with the MacDonald College. Paper and pencils. We do not do agriculture in an office. The time we take to fill the papers, we do not work. It's good if the government provides us with interest-free loans and grants. Even with agronomists: they provide us with good coaching but it is limited to a specific job. The credit union is not the 
best in terms of funding, but it's better than governmental programs. We must be aware of the new information (varieties and equipment). If we don't have experience, we should at least trust the experiences of other farmers" [Farmer B].

"Yes, we need help but it is not urgent. 1) Consulting services (agronomists). 2) Monetary aid $[F A Q$, government programs, e.g. the research and development program ( $R \& D)$, the Green Funds (Fonds Verts)]. It does not concern only agriculture; it is the entire population" [Farmer C].

"Yes, I need help. Support in terms of information (the MAPAQ logically and the vegetable seed companies for technology and practice)" [Farmer E].

"Yes, the help should come a little bit from everywhere. The government, the UPA, the Financière agricole du Québec. And the bank. Climate change will affect the Bio farms first, but there are no subsidies/supports for Organic Agriculture (vs. conventional farming)" [Farmer F].

"Yes, everyone needs help, especially in research! The agro-environmental clubs are the ones who can provide that help. For sure it is not the government because its administration is too slow!" [Farmer H].

"Yes, I need help. Agronomists (to know what changes to make). The Ministry of Agriculture and the FAQ for interest-free loans or grants (for financial assistance)" [Farmer E].

"No, I do not think farmers need help. In my opinion, any agricultural enterprise or farm should be profitable to survive itself. It is the money of the farmer that should always support himself / herself. If you do not have the sufficient amount of money, get out. If you continue to help the agricultural producers, they will always continue to ask for help. It's not fair that the government alone provides financial assistance; there are other actors in agricultural production. Furthermore, turkey production is the only production that never had help from the government. It works alone very well. This is the consumer's demand that plays an important role as well" [Farmer K].

"Yes, I need help. The government should invest in research (e.g. to maintain Good Soil because big equipment and machineries are causing soil compaction). But what is even better is the research done on the farm in cooperation with MAPAQ. The government should pay for the farms that are willing to do research, to encourage them. Agronomists help us in filling out the stack of papers for the government. The UPA and the CPTAQ (Commission de protection du territoire agricole du Québec) give us legal aid" [Farmer M].

"The government policy is not good at all, but not on the financial level (i.e. the bureaucracy goes too slowly). They are not realistic. They give subsidies for corn and soybeans only, but not for hay (we think of our cows and it is much better for the environment). We are punished because we do something good. In addition, you have to pay municipal taxes for forests but it does not work, it's not to our advantage. Municipal taxes must be removed and the government has to pay it like in Europe because it is not to our advantage. The government is taking good land for the development of 10-30 highway. Therefore, these are short-term 
solutions. I am not saying that I need a subsidy; the government always subsidizes things that are not good for the environment. We have to fill out so many papers; it is unbelievable! It is crooked when they announce that agriculture will receive millions of dollars as subsidies, but it is not for us, the producers, it's just to provide work for many officials leaving little room for farmers. For instance, the government makes one law for the Whole of Québec: You have to spread the manure during the growing season to protect the environment. However, the growing season in our region starts one month earlier and ends one month later, but the law does not change! So public policies should be more localized, taking into account the specific properties of each region" [Farmer J].

"Yes, I think that farmers need help. The UPA could do more. Agro-environmental clubs do a lot but it is private. Another problem is that each club includes 30-35 farmers as members, and the number of farmers who want to be associated with these clubs is increasing. So new agro-environmental clubs must be created; and this implies more money" [Farmer O].

\subsubsection{Determinants of Adaptive Capacity}

It is clear that there are several climatic and non-climatic factors that affect the decisions of farmers when adapting to CCV. These factors are considered as important elements of decisions as well. Question (11) eleven of the questionnaire let the participants provide the current to near-future principal determinants of adaptive capacity.

"It is getting warmer and warmer in the summer. The period is longer and there is a possibility of reseeding" [Farmer D].

"We mainly have to deal with excessive rain events; they have serious consequences on our farm" [Farmer O].

"Besides the economic factors play an important role, we need help from private agricultural services since the government is not advanced in providing us the support we need" [Farmer $\mathrm{K}]$.

"We need grants from the government. In addition, we need crop insurance since it is difficult to insure small but very diversified producers like us; we do not have one hectare for each vegetable" [Farmer G].

"In addition to climatic conditions, we need agricultural support (i.e. research) and financial assistance (e.g. grants specially to help us double the drainage)" [Farmer A].

"We need financial assistance and labour" [Farmer I]

Add to the latter the factors that the interviewees take into consideration before engaging in an adaptation activity. Apparently and while recognizing the importance of both factors, the respondents are keen on the fact that climatic and non-climatic factors cannot be held constant in the process of adaptation to CCV. Some of them even stated that one should not separate climatic from non-climatic factors in the process of agricultural adaptation to CCV. "Climatic and economic factors are on the same level of importance. Aside from that, we need farm succession, administrative research on the farm (i.e. accounting), and agricultural 
support (i.e. research)" [Farmer D].

\section{Discussion and Conclusions}

This study has as its objective to enhance the understanding of the adaptation process and adaptive capacity at the farm and farm community levels through a mostly bottom-up process based on a co-construction process, to develop appropriate management and planning tools and to build greater levels of capacity for adaptation in the farm community. To achieve this, Grounded Theory, which is a qualitative approach, was adopted in this research. Grounded Theory is one of the most common methods used in human geography. It generates a theory about a particular phenomenon from empirically observable data by giving the participants the chance to express their opinions. Primary and secondary data sources were used. Interviews are primarily related to the farmers who were the target audience of this research. A total of 15 farmers were asked a series of questions prepared in advance, covering aspects related to measures implemented that can render their farms more profitable, and to increase their appreciation of climate change and the strategies used to address CCV. It is important to note that 15 farmers do not quantitatively represent all the farmers in the RCM of Haut-Richelieu.

Agriculture faces many challenges. All the participants acknowledged the presence of CCV. And while some farmers recognized the positive and the negative side of $\mathrm{CCV}$, others are very optimistic about it and they only seem to see the positive side; hence the need to see both sides of CCV. Also, there is still an uncertainty related to CCV, which comes from disinformation and desensitization of the farmers mainly on the causes of CCV along with the nature of climatic events. Therefore, what Ilbery (1991) stated is still relevant to this study, which is: There would seem to be opportunities to reduce vulnerabilities to climatic variation not by developing new hybrids for this purpose, but by clarifying the nature of (and probabilities associated with) climatic variability, so that individuals can select hybrid mix strategies consistent with their risk preferences, rather than seemingly gambling recklessly with nature. We can add that human expectations regarding weather and climate scenarios sometimes lead to perceptions which are not supported by observational data (Mitchell and Tanner 2006). Short-extreme events are not necessarily an indicator of long-term shifts in climate (Mitchell and Tanner 2006), while it is important to note here that human perception of long-term tendencies are limited compared to short-term extreme events (Farhar-Pilgrim, 1985; Hamden 2016).

Though the vulnerability and adaptation practices (measures or strategies in other words) are not the same for all sectors of production, and can be even contradictory sometimes, the participants recognized that both climatic and non-climatic factors are important in the process of adaptation to CCV. For instance, a horizontal agricultural production (e.g. an orchard; a fruit that grows horizontally) requires more labor than a vertical one (e.g. corn or soya; vegetables that grow vertically). Adaptation is an irreversible process in the sense that agriculture adapts to climate but not vice versa. Like the co-construction of public policies, adaptation is not a one-shot event but a continuing process. Adaptation and the co-construction of public policies, programs and projects are not linear processes in the sense 
that they often take time - days, weeks, months, or years, and require iterative efforts shifting back and forth between stages. Also, both adaptation and co-construction are complex because they frequently involve climatic as well as socio-economic factors. And it is true that adaptation is a necessary complement to mitigation measures. However, mitigation naturally implies adaptation by many actors. Moreover, and while adaptation has many characteristics and types, there are plenty of forms of adaptation that involve both the private agent and the government. Although it is true that adaptation is often based on previous experiences, learning from previous mistakes often seems minimal because of two main reasons: (1) the complexity of causes and effects of CCV makes it difficult to pin down definitive lessons; and (2) adaptation is a complex and long process. The context (e.g. frequency and magnitude of events) can change by the time a lesson is learned. Finally, and as Mitchell and Tanner (2006) stated, adaptation is "an understanding of how individuals, groups and natural systems can prepare for and respond to changes in climate or their environment".

Furthermore, adaptation strategies should be developed jointly by farmers in concert with other actors, starting with the agronomists because they serve as important relays between farmers and other stakeholders such as public institutions and private companies. Co-construction is a planned adaptation strategy that includes the involvement of public actors with the consultation and involvement of private agents. And given the fact that the farmers in the RCM of Haut-Richelieu adapt spontaneously with the indirect involvement of the public agents, the co-construction process is not present yet to any substantial extent in the RCM of Haut-Richelieu. The governmental institutions should be directly (and increasingly) involved in the process of agricultural adaptation to CCV. Overall and according to the participants, the adaptive capacity in the RCM of Haut-Richelieu is good. However, if the public agent intervenes more, the adaptive capacity may well be enhanced. So yes, there is a possibility of co-construction in the RCM of Haut-Richelieu as there is always a place for improvement, but the sooner the better. For instance, the farmers' union arranges meetings with agronomists from time to time. These meetings should also include the farmers, along with other actors, of the region. What is even better is the adoption of appropriate adaptation tools by the government. An adaptation tool is a method that guides non-climate change experts through a series of analytical steps to examine the implications of climate change on their policies, programs, plans, and operations, and determine appropriate response options. It is noteworthy that the government alone cannot do all and hence cannot bear the consequences of climate change alone.

On a final note, implementing the co-construction approach is a way to develop new tools (or toolkits) in the fields of adaptation of agriculture to climate change and variability at the farm level in a decentralized (bottom-up) manner within a group of actors. This type of approach is used for connecting indicators and integrating and managing interaction between individual, collective and scientific knowledge. It is no longer the optimum which is sought but a compromise and this is reached by a dynamic process of progressive adjustment. This type of approach where practices which are considered to be positive or innovative are institutionalized is more likely to suit the diversity of actors' values. The approach combines 
action-research (progressive and collective learning) and grounded theory (beginning with data collection and then formulating a hypothesis or theory by comparative analysis). It is a pro-active approach. What makes it original is not only the participatory nature of the construction, but also the regional nature of the approach. In other words, it is an approach where adaptation takes place as a bottom-up process, with government stepping in to provide incentives and support (Akkari 2015).

\section{Acknowledgments}

We are thankful to Social Sciences and Humanities Research Council of Canada (SSHRC) for funding this study through the project "Adaptation and Vulnerability of Agriculture and Communities to Climate Change and Variability: Co-construction of Local and Regional Actions and Policies", SSHRC (Appels sur l'environnement), \$249,300, April 2009 - March 2012 (plus the usual extra year). C.R. Bryant is the principal researcher and director of the team. We are also thankful to the farmers and the agronomists who participated in this research.

\section{Authors' Contribution and Acknowledgments}

C.A. acquired, cleaned and analyzed the data and wrote and edited the manuscript. C.R.B. and C.M. edited the manuscript and supervised the entire study.

\section{Conflicts of Interest}

The authors declare that they have no competing interests.

\section{References}

Akkari, C. (2015). Adaptation of Agriculture to Climate Change in Québec: The Co-construction of Agricultural Policies in the RCM of Haut-Richelieu. Montréal: Département de Géographie, Université de Montréal, MSc thesis.

Akkari, C., \& Bryant, C. R. (2016). The co-construction approach to developing adaptation strategies in the face of climate change and variability: A Conceptual Framework. Agric Res, 5(2), 162-173. https://doi.org/10.1007/s40003-016-0208-8.

Bryant, C. R., Akkari, C., ..., \& Drouin-Lavigne, C. (2016a). The roles of governments and other actors in adaptation to climate change and variability: The examples of agriculture and coastal communities. AIMS ENVI SC, 3(3), 326-346.

https://doi.org/10.3934/environsci.2016.3.326.

Bryant, C. R., Akkari, C., ..., \& Drouin-Lavigne, C. (2016b). The Unintended Consequences of Government Action and Initiatives to Cope with Major Environmental Issues. Communication presented at the colloquium SALISES, Georgetown, Barbados. Conference paper, 8.

Coleman, J. S. (1959). Relational Analysis: The Study of Social Organizations with Survey Methods. Human Organization, 17, 28-36.

https://doi.org/10.17730/humo.17.4.q5604m676260q8n7 


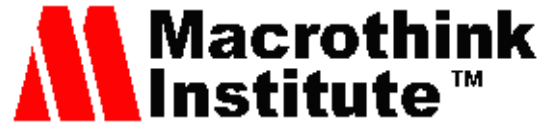

Journal of Agricultural Studies

ISSN 2166-0379

2017, Vol. 5, No. 2

Dale, A., Ling, C., \& Newman, L. (2010). Community Vitality: The Role of Community-Level Resilience Adaptation and Innovation in Sustainable Development. Sustainability, 2, 215-31. https://doi.org/10.3390/su2010215

Daouda, O., Bryant, C. R., \& Akkari, C. (2015). Social networks and the diffusion of innovations, towards a critical partnership for a successful adaptation strategy: a case study of agriculture in southwestern Quebec. International Journal of Climate Change: Impacts and Responses, 6(3-4), 37-58.

Dey, I. (1999). Grounding grounded theory: guidelines for qualitative inquiry. San Diego: Academic Press. https://doi.org/10.1016/b978-012214640-4/50011-5

Dick, B. (2000). Grounded-theory: a thumbnail check. 2000. Available online at: http://www.scu.edu.au/schools/gcm/ar/arp/grounded.html, or PDF:

http://www.aral.com.au/DLitt/DLitt_P59ground.pdf

Dilling, L., Lackstrom, K., ..., \& Kalafatis, S. (2015). What stakeholder needs tell us about enabling adaptive capacity: The intersection of context and information provision across regions in the United States. Wea Climate Soc, 7, 5-17.

https://doi.org/10.1175/WCAS-D-14-00001.1

Dunford, R., Harrison, P. A., ..., \& Tinch, R. (2015). Exploring climate change vulnerability across sectors and scenarios using indicators of impacts and coping capacity. Climate Change, 128, 339-354. https://doi.org/10.1007/s10584-014-1162-8

Fadul, J. A. (2007). Workbook for a course in general psychology. Published by Lulu Press, Inc. ISBN: 978-1-4303-2057-9.

Farhar-Pilgrim, B. (1985). Social Analysis. In Climate Impact Assessment Studies of International Climate and Society; Kates, R.W.; Ausubel, J.H.; Berberian, M. Chichester and New York, 323-350.

Glaser, B. G. (1998). Doing grounded theory. Issues and discussions. Mill Valley, CA: Sociology Press.

Glaser, B. G. (2001). The grounded theory perspective: Conceptualization contrasted with description. Mill Valley, CA: Sociology Press.

Glaser, B. G., \& Strauss, A. L. (1965). Awareness of dying. Chicago, IL. Aldine Publishing.

Goodman, L. A. (1961). Snowball Sampling. Annals of Mathematical Statistics, 32, 148-170. https://doi.org/10.1214/aoms/1177705148

Hamden, R. (2016). Planning for Climate Impacts that's Delivering Results - Using Behaviour Change Approaches to Deliver Far Reaching Reform. Presentation in the congress Adaptation Canada, April 14th 2016.

Ilbery, B. (1985). Agricultural Geography: a social and economic analysis. Oxford University Press, Oxford. 
Jongman, B., Hochrainer-Stigler, S., ..., \& Ward, P. J. (2014). Increasing stress on disaster-risk finance due to large floods. Nat Clim Chang, 4: 264-268.

https://doi.org/10.1038/nclimate2124

Mack, N., Woodsog, C., MacQueen, K. M., Guest, G., \& Namey, E. (2005). Qualitative Research Methods: a data's collector's field guide. Family Health International. Module 2: Observational skills.

McEvoy, D., Matczak, P., Banaszak, I., \& Chorynski, A. (2010). Framing adaptation to climate-related extreme events. Mitigation and Adaptation Strategies for Global Change, 15, 779-795. https://doi.org/10.1007/s11027-010-9233-2

Mitchell, T., \& Tanner, T. M. (2006). Adapting to climate change: challenges and opportunities for the development community. Tearfund, Teddington.

Pielke, R. A. (1998). Rethinking the role of adaptation in climate policy. Global Environmental Change, 8, 159-170. https://doi.org/10.1016/S0959-3780(98)00011-9

Reilly, J. (1995). Climate change and global agriculture: recent findings and issues. American Journal of Agricultural Economics, 77, 727-733. https://doi.org/10.2307/1243242

Risbey, J., Kandlikar, M., Dowlatabadi, H., \& Graetz, D. (1999). Scale, context, and decision making in agricultural adaptation to climate variability and change. Mitigation and Adaptation Strategies for Global Change, 4(2): 137-165. https://doi.org/10.1023/A:1009636607038

Smit, B., McNabb, D., \& Smithers, J. (1996). Agricultural adaptation to climatic variation. Clim.Change, 33, 7-29. https://doi.org/10.1007/BF00140511

Smit, B., \& Skinner, W. M. (2002). Adaptation options in agriculture to climate change: A typology. Mitigation and Adaptation Strategies for Global Change, 7, 85-114. Kluwer Academic Publishers. https://doi.org/10.1023/A:1015862228270

Stern, P. N. (2007). On solid ground: essential properties for growing grounded theory. In: Bryant \& K. Charmaz (Eds.). The SAGE handbook of grounded theory, 114-126. London: Sage. https://doi.org/10.4135/9781848607941.n5

\section{Copyright Disclaimer}

Copyright for this article is retained by the author(s), with first publication rights granted to the journal.

This is an open-access article distributed under the terms and conditions of the Creative Commons Attribution license (http://creativecommons.org/licenses/by/4.0/). 